\title{
Internship in Greece: The Case of University of Peloponnese
}

\author{
George Kipreos \\ Dept. of Sport Management, University of Peloponnese \\ Valioti \& Plataion Avenue, PC 23100, Sparta, Greece \\ Tel: 0030-2731089668Ｅ-mail: kipreos@uop.gr \\ Panagiotis E. Dimitropoulos (Corresponding author) \\ Dept. of Sport Management, University of Peloponnese \\ Valioti \& Plataion Avenue, PC 23100, Sparta, Greece \\ Tel: 0030-2731089677Ｅ-mail: dimitrop@uop.gr
}

\author{
Vassilios Poulopoulos \\ Department of Informatics and Telecommunications, \\ University of Peloponnese, End of Karaiskaki st., 22131, Tripolis \\ Email: vacilos@uop.gr
}

Received: December 18, 2016 Accepted: February 05, 2017 Published: March 14, 2017 doi:10.5296/ijld.v7i1.10917 URL: http://dx.doi.org/10.5296/ ijld.v7i1.10917

\begin{abstract}
The activity of internship is indispensable to a large number of university departments in order for the students to achieve educational goals and be able to receive their degree. We present the case of University of Peloponnese and the level of satisfaction of the students who have attended internship to public and private bodies. Moreover, we present statistical information concerning the number of students and different providers that took part in the procedure of internship during the last 12 months. Finally, according to answers from students concerning the usability of internship to their career and future, despite the fact that many of them do not agree that they managed to receive a remarkable level of expertise in a specific field, a large number of them was engaged to the private companies that they were occupied to, leading to the conclusion that both the students and the companies invested in
\end{abstract}


their relation.

Keywords: Academic internship, students' career, University of Peloponnese, Greece.

\section{Introduction}

Internship programs have been incorporated into the curricula of the majority of academic institutions worldwide, in order to provide field experience opportunities to the students (Kipreos \& Dimitropoulos, 2016). Teaching students how to apply the theoretical knowledge acquired in the classroom must be the ultimate goal of an academic institution (Khalil, 2015). It is inevitable that the majority of the educational hours within a university are related to theory while many of them are also spent in labs. The students have the opportunity to examine parts of their research or working environments either in theory or in a laboratory where in general the conditions tend to be perfect. This means that they do not have actual and real opportunities to face a working environment and realize how their acquired knowledge is depicted on the everyday routine.

Internship programs worldwide are usually performed within a specific time limit, they have specific work hours, are supervised by academic stuff and a corporate counterpart and usually receive some kind of award at the end of the procedure (Hergert, 2009; Khalil, 2015). In fact the procedure seems to be originating from a laboratory with very few levels of freedom both on the part of the companies and the students. Studies proved that turning from theory to the real world is a tedious task and a preparation of the procedure, even though a sterile procedure could help the students adapt to the needs of their working environment. In the studies of Alpert et al. (2009) and Maynes (2013), this issue is analyzed and discussed in order to conclude that students fulfilling internship are far more concerned rather the ones that never did. More precisely the first study proves that students from economic and business universities are exceptional in theory but when it comes to solving real business problems it seems that they lack significant initiative, while on the other side it is clearly stated that the benefits of service learning for students span from greater awareness of the links between theory and practice to social and environmental issues.

A large number of positive aspects have been recorded which are related to internship of students. Actually, the aspects differentiate between students of different fields of study but in general the outcome is better preparation for a working environment. For the theoretical sciences it is visible that students seem to have more effective communication, social awareness, voluntarism and critical thinking while the exact sciences are keen on gaining technical skills (Khalil, 2015). For both teams of students it is expected that they will benefit from acquiring skills like self-fulfillment, productivity, and teamwork and improve employability, personal skills and professional development (Alpert, 2009). In fact, an issue that is of our concern, as well, is that many of the students that are employed to a private company tend to have more proposals, permanent employment or even remuneration (Clark, 2003), while in parallel recruiters searching for young employers are further more attracted by students who have completed internship rather than the ones that have not (Binder et al., 
2015).

The last years it has become a trend of the colossal companies or even public bodies to engage with students in order to fulfill their internship. Moreover, they turn internship into some kind of "summer school" or "goal-by-goal" procedure. Through this, they actually have multifold benefits. Internship is transformed into an education step so that the company earns a two-month or three-month period of adaptation with the student. In parallel, the company lets the student learn their environment and enables them to position themselves in it. Finally, they know the exact profile of a future prospect without even having to spend time or money of any crucial procedure. It is inevitable that internship would not be able to flourish if it was not for the companies which are able to hire the students' even right after the end of the procedure. This procedure would furthermore save recruiting costs and employment risks (Kwan, 2005). Students can provide an edge on the daily operations of an organization since they bring novel ideas and offer some truthful and objective viewpoints for the business and the industry (Lee \& Chao, 2013) and they are able to undertake risk-free small projects which sometimes are not considered to be profitable for a company.

However, despite the fact that the benefits of internship have been proved by several researchers within different scientific fields, those benefits may not accrue if the internship programs are not carefully considered, assessed and organized (Kipreos \& Dimitropoulos 2016). The negative experiences of students from the internship programs are significant determinants of students' decision to seek and accept a job position within the specific business sector (Lee \& Chao 2013). This means that the procedure of the internship program should really have a balance between the level of freedom that must be given to the students and the companies and the supervision by members of the academic staff. The supervision should not be static and the knowledge must not be superficial. The academic staff must have deep knowledge of each proposed position, of the students' skills and their willing to work. Especially in the occasions where students have to fulfill their internship in order to receive a degree it is more than necessary to have a completely different approach on the connection between students and companies.

In this study we present the case study of internship in University of Peloponnese. We analyze the statistics of students' responses regarding their internship experience, internship companies and their relation together with statistics of the students' evaluation of the procedure and the accepting companies. Our study adds into a significant body of literature regarding students' experience form academic internship programs and is the first study in Greece trying to evaluate perceptions from the population of students instead a sample of students from a specific academic unit (department) as in the study of Kipreos and Dimitropoulos (2016). The rest of the paper is structured as follows: The next section provides details about the internship program at the University of Peloponnese. The third section presents statistics collected the last 12 months about the internship last section concludes the paper offering useful policy implications and directions for future research.

\section{University of Peloponnese internship program}

The University of Peloponnese was founded in 2002. Today it consists of 9 departments: 
Department of Economics, Department of Informatics and Telecommunications, Department of History, Archaeology and Cultural Resources Management, Department of Philology, Department of Social and Education Policy, department of Political Science and International Relations, Theatre studies department, department of sport management and department of nursing. Students from all the departments can take part in the internship program which lasts either 2 or 3 months according to the department. In 4 out of the 9 departments the internship is obligatory meaning that the students have to complete their internship in order to receive their degree. In the rest 5 departments the internship is optional but its fulfillment is equivalent to succeeding to a university lesson.

Each of the departments have their own approach towards the internship program as each one of them has their own particularities. The department of economics usually tends to select banks as the companies of internship as they are considered to be the heart of the economy system. The bank as a business has a very wide cycle of procedures most of them related to the real economy. In this way they are at least assured that students from their department can have an overview of what they learnt about economy in theoretical level.

The department of Informatics and Telecommunications is closely related to the IT sector and despite the fact that for many years most of the students were attracted by major telecommunication companies the last years they tend to select small and medium IT companies in order to have a deeper knowledge of a specific part of their field. Students from the Department of History, Archaeology and Cultural Resources Management are usually selecting and selected by ministries and generally public bodies related to education and culture while in parallel many private companies including Scientific and Cultural Foundations, Private Museums and companies taking over restoration projects are really interested for them.

The department of philology is more directed to the educational procedure and the selection of schools and libraries from the student is the majority of the choices. The department of social and educational policy is selected from companies, public or private, those are mostly engaged to some kind of educational procedure and could be helped by students knowing social and educational policies. Public and private bodies selected by the department of Political Science and International Relations include institutes for international relations, institutes for economy relations, ActionAid, Doctors of the World, the Greek Parliament and more. The theater studies department is usually selecting related companies (theaters, public bodies related to culture, etc) while sports management department can select one from the large variety of sports clubs for any different type of sports each student is really interested in. Finally the department of nursing is one of the most important in the execution of the internship as its students are selected by hospitals (mainly public) which are in strong need of nursing personnel.

For the internship in the University of Peloponnese a hierarchy of services exists. The whole internship program is organized by a centralized office of the internship. The office consists of both administrative and technical staff. As every different department has their own needs in terms of internship a local office for the internship is organized in every different 
department. The office is organized by a member of the faculty who is responsible for a large number of procedures mainly including the smooth execution of the internship, the satisfaction of both the students and the carriers, the correct matching between students and carriers according the students skills and the carrier job description as well as a number of administrative procedures needed to complete the procedure. The whole procedure is supervised by the institutional responsible for the internship.

The internship in Greece is organized by a system named ATLAS ${ }^{1}$, while every local University and Technological Institute have their own implementation of a platform for the internship that interconnects through web services with the centralized system. Organizing the students and the staff to adapt to a novel system (the local platforms where introduced 10 months ago) is not an easy procedure but with the support of the platform implementers the procedure turned to be easy and smooth. The procedure of position selection is as follows:

- Carriers post job descriptions/positions and the specialty of preference for each object

- Students that are eligible for fulfilling internship apply for the positions

- The department's faculty responsible for the internship performs a cross-check in order to assure that students have the necessary skills for each selected position

- Companies express their interest for the students that selected them

- Students select the company that picked them and they like most

After the finalization of the procedure the student is ready to start their internship at the time schedule that is pre-organized to be some time in the year. For the educational year 2016-2017 a total number of 517 internship position is available and funded, while more than 350 were completed the last 10 months. From these 225 are obligatory to be fulfilled as part of curriculum of the corresponding departments while 292 are not obligatory.

\section{Internship statistics}

In this section we present the statistics of the internship of the last 10 months. Having already completed a circle of internships during the months July 2017 to October 2017 we are currently preparing a second circle with some of the departments already executing their second circle of internships. The following table presents the number of successfully completed internships the last 10 months.

\footnotetext{
${ }^{1}$ http://atlas.grnet.gr
} 
Table 1. Distribution of successfully completed internship posts

\begin{tabular}{|l|l|}
\hline Department & $\begin{array}{l}\text { Successfully } \\
\text { completed }\end{array}$ \\
\hline Theatre studies & 30 \\
\hline History, Archaeology and Cultural Resources Management & 65 \\
\hline Social and Educational policy & 23 \\
\hline Nursing & 62 \\
\hline Economy & 30 \\
\hline Sports management & 55 \\
\hline Informatics and Telecommunications & 11 \\
\hline Political Science and International Relations & 15 \\
\hline Philology & 63 \\
\hline Total & $\mathbf{3 5 4}$ \\
\hline
\end{tabular}

From the starting number of 359 students only 4 did not manage to complete their internship mainly due to parallel activities that could not let them have free time for their internship. After the completion of the procedure the students are called to evaluate the procedure of the internship towards a number of different fields. A first approach to this evaluation is provided by a simple question if they believe they earned any practical knowledge related to their field of studies. As the question is plain yes or no question it is generally observed that the answers vary not necessarily from student to student but from department to department. As such, students from Nursing department that are usually engaged to a carrier very close to their field of studies tend to answer yes to this question as they really have deeper knowledge of their specialty. The results of this question revealed for the University of Peloponnese that $40 \%$ of the students agree that they acquired some kind of specialty related to their field of studies, a percentage that seems to be relatively high if we consider the nature of the question.

As already mentioned this is just a question of a part of their obligation to complete the internship. Moreover, we provided with an optional questionnaire in order to have a general image of the carriers and the work that is done by them in cooperation with the students. The following table presents the results to the questions answered by the students. According to 
the questionnaire, answer 1 represents Poor score while answer 5 represents Excellent score.

Table 2. Questionnaire responses

\begin{tabular}{|c|c|c|c|c|c|}
\hline Question & 1 & 2 & 3 & 4 & 5 \\
\hline $\begin{array}{l}\text { You think your theoretical } \\
\text { knowledge helped in the work } \\
\text { you have undertaken? }\end{array}$ & $\begin{array}{l}4 \\
(2 \%)\end{array}$ & $\begin{array}{l}7 \\
(4 \%)\end{array}$ & $\begin{array}{l}24 \\
(12 \%)\end{array}$ & $\begin{array}{l}110 \\
(54 \%)\end{array}$ & $\begin{array}{l}57 \\
(28 \%)\end{array}$ \\
\hline $\begin{array}{l}\text { You think your practical } \\
\text { knowledge helped in the work } \\
\text { you have undertaken? }\end{array}$ & $\begin{array}{l}4 \\
(2 \%)\end{array}$ & $\begin{array}{l}3 \\
(1.5 \%)\end{array}$ & $\begin{array}{l}11 \\
(5.5 \%)\end{array}$ & $\begin{array}{l}91 \\
(45 \%)\end{array}$ & $\begin{array}{l}93 \\
(46 \%)\end{array}$ \\
\hline $\begin{array}{llr}\text { The tasks } & \text { which } & \text { you } \\
\text { undertook } & \text { met } & \text { your } \\
\text { expectations? } & & \end{array}$ & $\begin{array}{l}1 \\
(-)\end{array}$ & $\begin{array}{l}2 \\
(1 \%)\end{array}$ & $\begin{array}{l}13 \\
(6 \%)\end{array}$ & $\begin{array}{l}69 \\
(34 \%)\end{array}$ & $\begin{array}{l}117 \\
(59 \%)\end{array}$ \\
\hline $\begin{array}{l}\text { Did you have good support } \\
\text { from the carrier's personnel? }\end{array}$ & $\begin{array}{l}1 \\
(-)\end{array}$ & $\begin{array}{l}0 \\
(-)\end{array}$ & $\begin{array}{l}3 \\
(1.5 \%)\end{array}$ & $\begin{array}{l}29 \\
(15 \%)\end{array}$ & $\begin{array}{l}169 \\
(83.5 \%)\end{array}$ \\
\hline $\begin{array}{l}\text { The time that you spent was } \\
\text { enough in order to acquire } \\
\text { expertise? }\end{array}$ & $\begin{array}{l}62 \\
(31 \%)\end{array}$ & & & & $\begin{array}{l}140 \\
(69 \%)\end{array}$ \\
\hline $\begin{array}{l}\text { The accepting organization is } \\
\text { suitable for students' } \\
\text { internship? }\end{array}$ & $\begin{array}{l}1 \\
(-)\end{array}$ & $\begin{array}{l}5 \\
(2.5 \%)\end{array}$ & $\begin{array}{l}5 \\
(2.5 \%)\end{array}$ & $\begin{array}{l}31 \\
(15 \%)\end{array}$ & $\begin{array}{l}160 \\
(80 \%)\end{array}$ \\
\hline
\end{tabular}

In the aforementioned table we may observe that the results of the internship are exceptional. More than $85 \%$ of the students believe that they acquired a position that was so relative to their theoretical background that it was easy for them to do the work (Sum of answers larger than 3). The explanation of this answer means that the level of the theory is such that it seems to be helpful for the students to find a position that they could fulfill. In parallel this means that the positions are carefully selected so that the students will not be disappointed.

Proceeding to the second question, if the students have the practical knowledge to overcome the obstacles of the work they undertook the result is vast and the answers of 4 and 5 are more than $90 \%$. The students have acquired practical knowledge that is sufficient in order to fulfill their internship's work description. Again, we have to point out that the correctly selected matching between students and carriers is essential. 
A tricky but the most important question according to our opinion is the third one, which is if the work me their expectations. It is very important for an internship program to be able to meet the student's expectations in order to be assured that they will at least fulfill a job that is within their interests. One more time the results acquired are extremely good as $93 \%$ of the students' state that the job met their expectations.

Going on the side of the accepting organizations we asked if the accepting organizations' staff was willing to helping order to receive the outstanding percentage of $98 \%$ positive answers. The outcome is twofold. First of all, it seems that the students and faculty members are selecting high level and high quality carriers while in parallels the carriers are investing in the internship and they are putting their focus and attention to the students. This also derives from the question of carrier suitability for the internship which receives $95 \%$ positive answers. Finally, and not unexpected after all these positive answers, despite the fact that $69 \%$ of the students believe that the time was enough in order to acquire expertise a $31 \%$ percent of them state that they wanted it to be more.

\section{Conclusion}

We analyzed the case of internship at the University of Peloponnese and presented statistics that derive either from the internship itself but mainly from the questionnaires that the students are completing at the end of the procedure. It is inevitable from the answers presented that the procedures done at the University of Peloponnese lead to a successful internship at least from the student's perspective. The scope of the analysis was to present how the experience acquired from many years of running the internship program led to high levels of satisfactions.

Despite having high levels of satisfaction among the students that fulfill the internship we should try harder in order to a. keep the levels of satisfaction to a very high standard and $b$. attract more high level carriers to participate to the internship program. In parallel, even if the cases of dissatisfaction are few they are the real ones to be considered deeply and furthermore analyzed in order to understand what the problem was and find solutions for the students.

In the future, we will perform analysis from the questionnaires of the carriers in order to present their visual aspect of the internship program and actually try to do a combination of the different approaches (student VS carrier) especially when analyzing the matching position.

\section{References}

Alpert, F., Heaney, J., \& Kuhn, K. (2009). Internships in marketing: goals, structures and assessment-student, company and academic perspectives. Australasian Marketing Journal, 17(1), 36-45. http://dx.doi.org/10.1016/j.ausmj.2009.01.003

Binder, J.F., Baguley, T., Crook, C., \& Miller, F. (2015). The academic value of internship:

Benefits across disciplines and student backgrounds. Contemporary Education Psychology, 41, 73-82. http://dx.doi.org/10.1016/j.cedpsych.2014.12.001 


\section{Macrothink}

International Journal of Learning and Development

ISSN 2164-4063

2017, Vol. 7, No. 2

Clark, S.C., (2003). Enhancing the educational value of business internships. Journal of

Management Education, 27(4), 472-484. http://dx.doi.org/10.1177/1052562903251350

Hergert, M. (2009). Students perceptions of the value of internships in business education.

American Journal of Business Education, 2(8), 9-13. http://dx.doi.org/10.19030/ajbe.v2i8.4594

Kipreos, G., \& Dimitropoulos, P. (2013). Internship and employment opportunities: The case of the Department of Sport Management, University of Peloponnese. Conference proceedings on "The internship on the Academic Institutions", Iraklio Crete, Greece 17-18 October 2013, 91-95.

Kipreos, G \& Dimitropoulos, P. (2016). Academic Internship and Students' Satisfaction:

Evidence from Greece. Journal of Studies in Education, 6(3), 21-31. doi:10.5296/jse.v6i3.9536

Khalil, O.E.M. (2015). Students' experiences with the business internship program at Kuwait

University. The International Journal of Management Education, 13, 202-217. http://dx.doi.org/10.1016/j.ijme.2015.05.003

Kwan, F.V.C. (2005). Effect of supervised work experience on perception of work in the tourism and hospitality industry. Journal of Human Resources in Hospitality and Tourism, 4(2), 65-82. http://dx.doi.org/10.1300/J171v04n02_04

Lee, C-S., \& Chao, C-W. (2013). Intention to "leave" or "stay" - The role of internship organization in the improvement of hospitality students' industry employment intentions. Asian Pacific Journal of Tourism Research, 18(7), 749-765. http://dx.doi.org/10.1080/10941665.2012.695290

Maynes, N., Hatt, B., \& Wideman, R. (2013). Service learning as a practicum experience in a pre-service education program. Canadian Journal of Higher Education, 43(1), 80-99.

\section{Copyright Disclaimer}

Copyright for this article is retained by the author(s), with first publication rights granted to the journal.

This is an open-access article distributed under the terms and conditions of the Creative Commons Attribution license (http://creativecommons.org/licenses/by/3.0/). 